\title{
THE PHYSICAL PROPERTIES OF NORMAL LUNGS REMOVED AFTER DEATH
}

\author{
BY \\ M. B. McILROY \\ From the Medical Professorial Unit, St. Bartholomew's Hospital, London
}

(RECEIVED FOR PUBLICATION OCTOBER 6, 1952)

It has been known for over a century that the lungs retain some of their elastic properties after death. Carson (1820) was the first to investigate the elastic recoil of the lungs by measuring the force required to inflate them, and this type of experiment has been repeated by numerous investigators with confusing results. The only conclusion that can be drawn from the literature is that the elastic properties of normal lungs after death are unpredictable. In the experiments to be described the lungs have been inflated by negative pressure in a plethysmograph, and some of the factors responsible for changes in elastic behaviour after death have been analysed in an attempt to explain why previous investigations have not given consistent results.

Pulmonary elasticity has been defined as the ability of the lungs to recover their original size by elastic recoil when a force deforming them is removed. Until recently the lungs have been thought to obey Hooke's law, which states that the deformation of an elastic body is directly proportional to the force applied. This is a theoretical law to which no known material conforms. Recent work on the elastic properties of biological materials suggests that the lungs are more probably visco-elastic. A visco-elastic system is a combination of a viscous system in which the response to a force depends on the time the force is applied, and an elastic system in which the response depends on the magnitude of the force applied.

\section{Methods}

The material studied consisted of human lungs removed between six and 72 hours after death, and animal lungs, in some cases removed immediately after death. Before removal a brass tube was inserted into the trachea at about the level of the cricoid cartilage and clamped in position with a "jubilee" clip. A water manometer was connected to the intratracheal tube and the pressure generated by elastic recoil measured on opening the pleural cavity. The lungs, with the intratracheal tube occluded to prevent the escape of air, were then removed with the visceral pleura intact; the heart was cut off by severing the great vessels and the lungs set up in the plethysmograph without delay.

The plethysmograph consisted of an air-tight perspex box standing on a perspex tray with a mercury seal (Fig. 1). The lungs were suspended in the box with the intratracheal tube projecting through the top. The pressure in the box was reduced either by a vacuum pump or a simple hand pump until the pressure in the trachea was atmospheric. The intratracheal tube was then connected to the spirometer. Pressure changes in the plethysmograph were measured by a water manometer recording on a kymograph, or by a capacitance gauge. Although the water manometer showed lag and overswing, the error involved in its use was shown to be negligible under the conditions of the experiments. The volume of air passing in and out of the lungs was measured by a spirometer and recorded on the kymograph drum below the pressure.

Using the plethysmograph, it was possible to ventilate the lungs and measure their volume by the helium dilution method using the circuit described by Bates and Christie (1950). The intratracheal tube was connected to the lung volume circuit and the lungs ventilated until mixing was complete. Helium in air was used instead of helium in oxygen to eliminate the initial period of ventilation with oxygen.

\section{RESULTS}

From measurements of lung volume after inflation in the plethysmograph it was clear that the volume of air in the lungs when they were first set up in the p'ethysmograph was small. This finding suggested that air had escaped from the lungs between the time of death and removal of the lungs from the thorax. To confirm this suggestion a series of experiments was carried out.

In four cases the lungs were allowed to deflate completely in situ by opening the pleural cavity with the intratracheal tube connected to a bag. The volumes of air expelled are shown in Table $I$. The largest volume $(650 \mathrm{ml}$.) was expelled in a case investigated six hours after death. In three other patients investigated between 33 and 65 hours after death the volume expelled was less than $200 \mathrm{ml}$. 


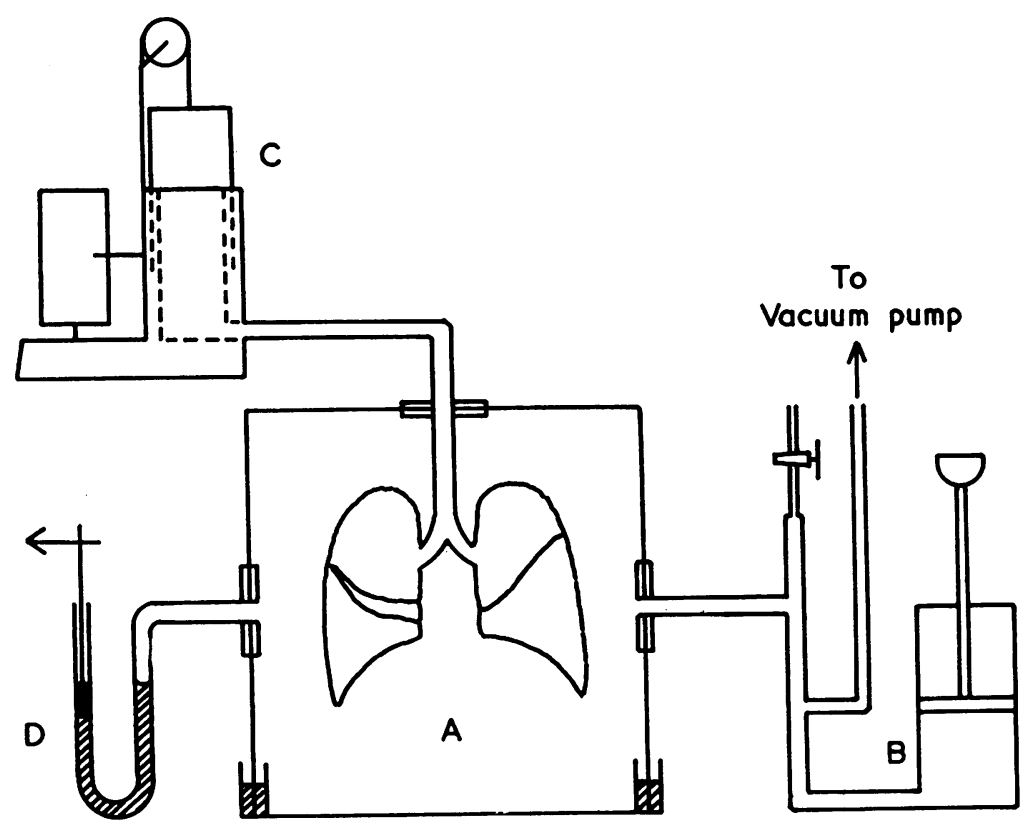

FIG. 1.-Diagram of apparatus. $A=$ airtight plethysmograph; $B=$ hand pump; $C=$ recording spirometer; $\mathrm{D}=$ water manometer.

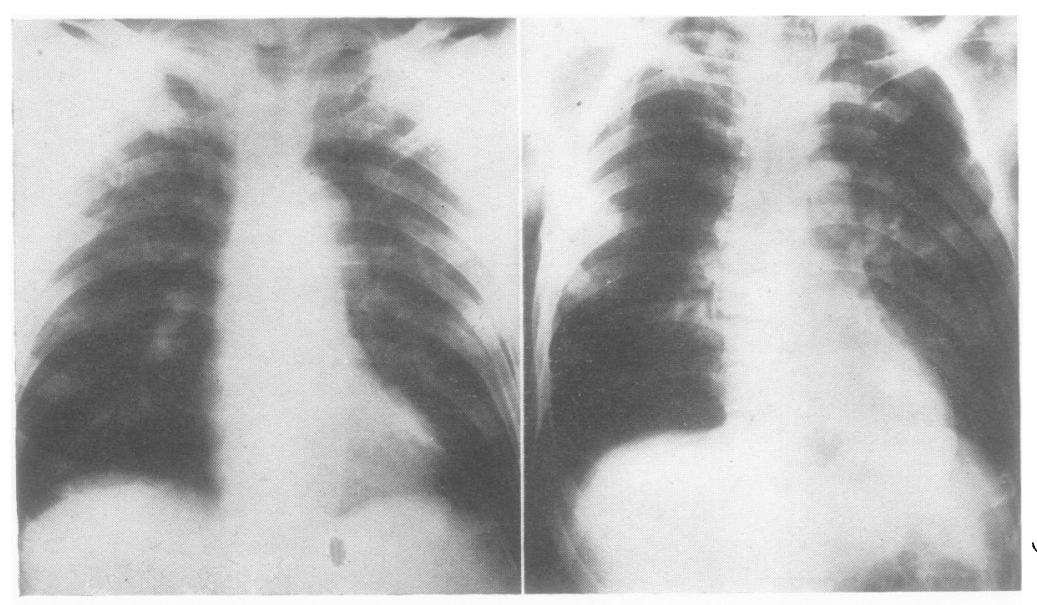

(a)

FIG. 2.-Radiographs of chest $(a)$ ante-mortem and $(b)$ post-mortem, showing ascent of diaphragm

TABLE I

VOLUMES OF AIR EXPELLED FROM THE LUNGS BY ELASTIC RECOIL ON OPENING THE PLEURAL CAVITIES AT NECROPSY

\begin{tabular}{|c|c|c|c|c|}
\hline $\begin{array}{c}\text { Time After } \\
\text { Death } \\
\text { (hours) }\end{array}$ & $\underset{\text { (years) }}{\text { Age }}$ & $\begin{array}{c}\text { Intra- } \\
\text { tracheal } \\
\text { Pressure } \\
\left(\mathrm{cm} . \mathrm{H}_{2} \mathrm{O}\right)\end{array}$ & $\begin{array}{l}\text { Volume } \\
\text { of Air } \\
\text { Expelled } \\
(\mathrm{ml} .)\end{array}$ & Cause of Death \\
\hline $\begin{array}{r}6 \\
33 \\
57 \\
65\end{array}$ & $\begin{array}{l}59 \\
44 \\
56 \\
65\end{array}$ & $\begin{array}{l}3 \cdot 5 \\
2 \cdot 8 \\
5 \cdot 2 \\
3 \cdot 4\end{array}$ & $\begin{array}{r}650 \\
60 \\
120 \\
180\end{array}$ & $\begin{array}{l}\text { Perforated gastric ulcer } \\
\text { Cerebral haemorrhage } \\
\text { Cerebral tumour }\end{array}$ \\
\hline
\end{tabular}

(b)

The volume of air that would be expelled if the pleura cavities were opened during life is probably of the orde\& of $1,500 \mathrm{ml}$., and the smats volumes expelled in these post-mortem experiments particularly those betweeg 33 and 65 hours after deatl? suggested that the lungs hat deflated in the period bed tween death and necropsy. $\vec{t}$

The change in lung volums after death was further irs vestigated by passing a cuffed. intratracheal tube soon aftex death and collecting the ex pelled air in a bag. Six cases were investigated in this wa the intratracheal tube being inserted under direct visios between 20 minutes and tw:O and a half hours after deat? Results are shown in Tabe II. It can be seen that the sooner the collection of a a was started after death the larger the volume collected: In the case in which the intratracheal tube was inse표 ted 20 minutes after dea $845 \mathrm{ml}$. was collected, $550 \mathrm{~m}$ out of this total being collee ted in the first two hours. $\ddot{x}$

Reduction in lung volunie after death was also inves gated by comparing radia graphs taken before and after death. Antero-posterior films were taken in tudo patients before and 24 hou after death. In each case thg position of the patient $\frac{-}{N}$ supine at the end of expiris tion-and the tube distances were the same. The difference between ante-mortem and post-mortem radidgraphs is seen in Fig. 2; there is clearly ascent of the diaphragm after death. This was confirmed by planimetric measurement of the area of lung fields which showed a $12 \frac{1}{2} \%$ reduction after deat.

These findings confirmed that a large amount of air was expelled from the lungs between death and necropsy, probably by ascent of the diaphragí. As a result, the lungs, when first set up in the 
TABLE II

VOLUMES OF AIR EXPELLED FROM THE LUNGS BETWEEN DEATH AND NECROPSY

\begin{tabular}{|c|c|c|c|}
\hline $\begin{array}{l}\text { Time of In- } \\
\text { sertion of Tube } \\
\text { (minutes } \\
\text { after death) }\end{array}$ & $\underset{\text { (years) }}{\text { Age }}$ & $\begin{array}{c}\text { Volume of Air } \\
\text { Collected } \\
\text { (ml.) }\end{array}$ & Cause of Death \\
\hline $\begin{array}{r}20 \\
60 \\
60 \\
120 \\
120 \\
120 \\
150\end{array}$ & $\begin{array}{l}55 \\
59 \\
66 \\
78 \\
38\end{array}$ & 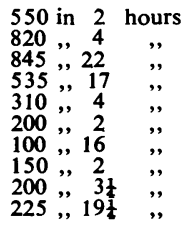 & $\begin{array}{l}\text { Carcinoma of pancreas } \\
\text { Coronary thrombosis } \\
\text { Perforated gastric ulcer } \\
\text { Carcinomatosis } \\
\text { Pulmonary embolism } \\
\text { Acute leukaemia }\end{array}$ \\
\hline
\end{tabular}

plethysmograph, were not inflated to the same volume as they had been in life.

Plethysmograph EXPERIMENTS. - The first expansion of the lungs in the plethysmograph was produced by reducing the pressure in steps of $2 \mathrm{~cm}$. $\mathrm{H}_{2} \mathrm{O}$ to about $10 \mathrm{~cm}$. below the starting pressure, and a typical tracing is shown in Fig. 3. During inflation collapsed areas on the surface of the lungs were seen to expand one after another. The time needed for equilibrium to be reached at intermediate pressures was so long that a serious attempt to reach equilibrium was only made after the last step. The lungs were then allowed to recoil by increasing the pressure to its original level in similar steps. The volume change was larger with each successive step, indicating that the lungs did not obey Hooke's law. Equilibrium was readily reached after each pressure step during recoil, but the lungs failed to recoil to their starting level.

In the experiment shown in Fig. 3 the postmortem lung volume was initially $1,346 \mathrm{ml}$. After the first inflation the lungs recoiled to a volume of $2,206 \mathrm{ml}$., a value within the normal range of the functional residual air. A comparison between the post-mortem lung volume and the lung volume after inflation in 13 normal lungs is given in Table III, from which it can be seen that the first inflation of the lungs in the plethysmograph restored the lungs to a volume more comparable with that in life, presumably by opening up alveoli which had become airless after death.

The lung volume and presumably the number of alveoli opened up in this first inflation depended on how far the plethysmograph pressure was reduced. The arbitrary reduction to $10 \mathrm{~cm} . \mathrm{H}_{2} \mathrm{O}$ below the starting level was found to be satisfactory, for the alveoli on the surface of the upper lobes of the lungs were usually all expanded at this level.

The opening up of previously collapsed alveoli resulted in a complicated relation between pressure and volume which varied with each inflation as shown in Fig. 4. At. A, when the pressure was -4.8 $\mathrm{cm}$. $\mathrm{H}_{2} \mathrm{O}$, the lung volume was $770 \mathrm{ml}$. above the
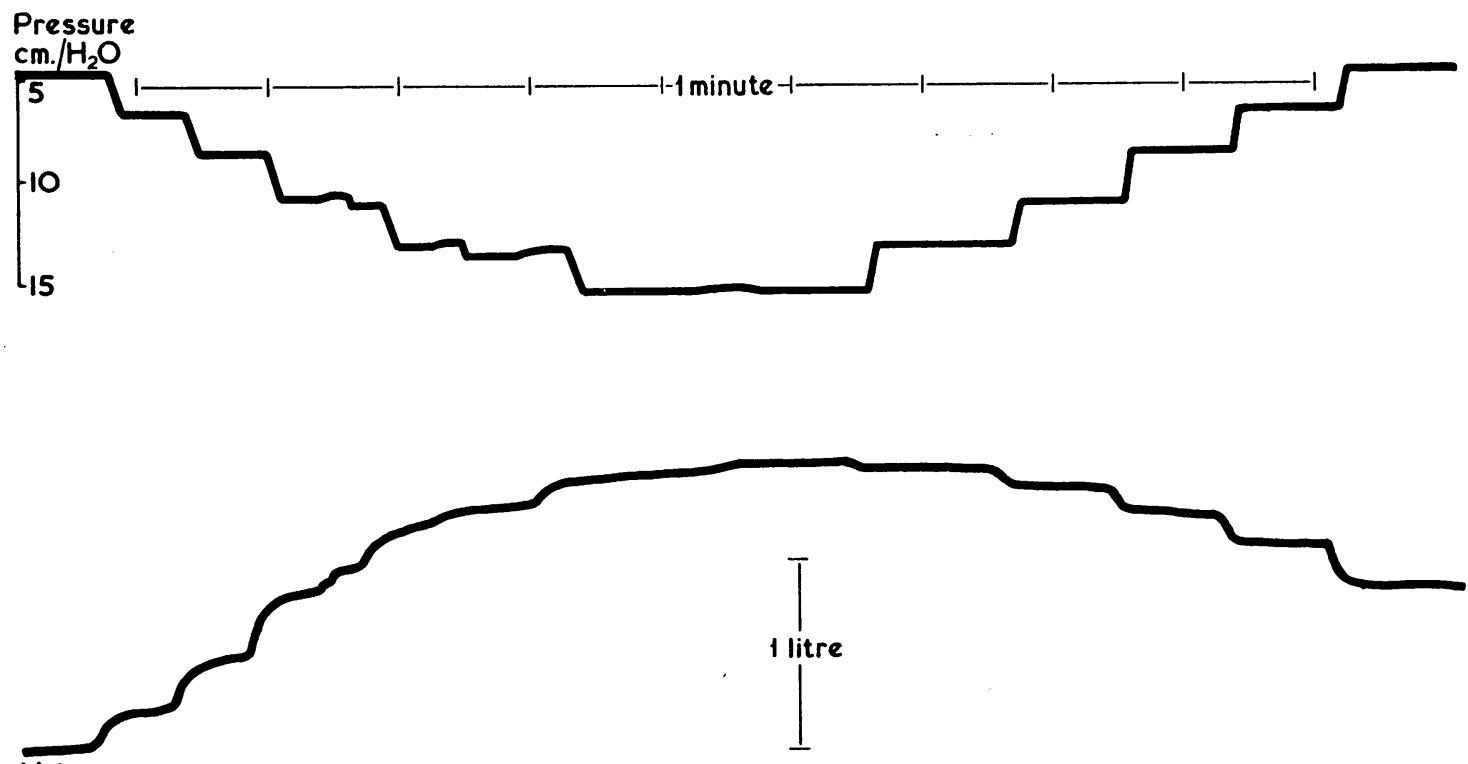

Volume

FIG. 3.-Tracing of first inflation of normal lungs in plethysmograph, showing failure to obey Hooke's law. Upper tracing represents plethysmograph pressure and lower tracing volume of air passing in and out of the lungs. 
TABLE III

RESULTS IN EIGHTEEN NORMAL HUMAN AND FOUR DOGS' LUNGS INVESTIGATED AT DIFFERENT INTERVALS AFTER DEATH

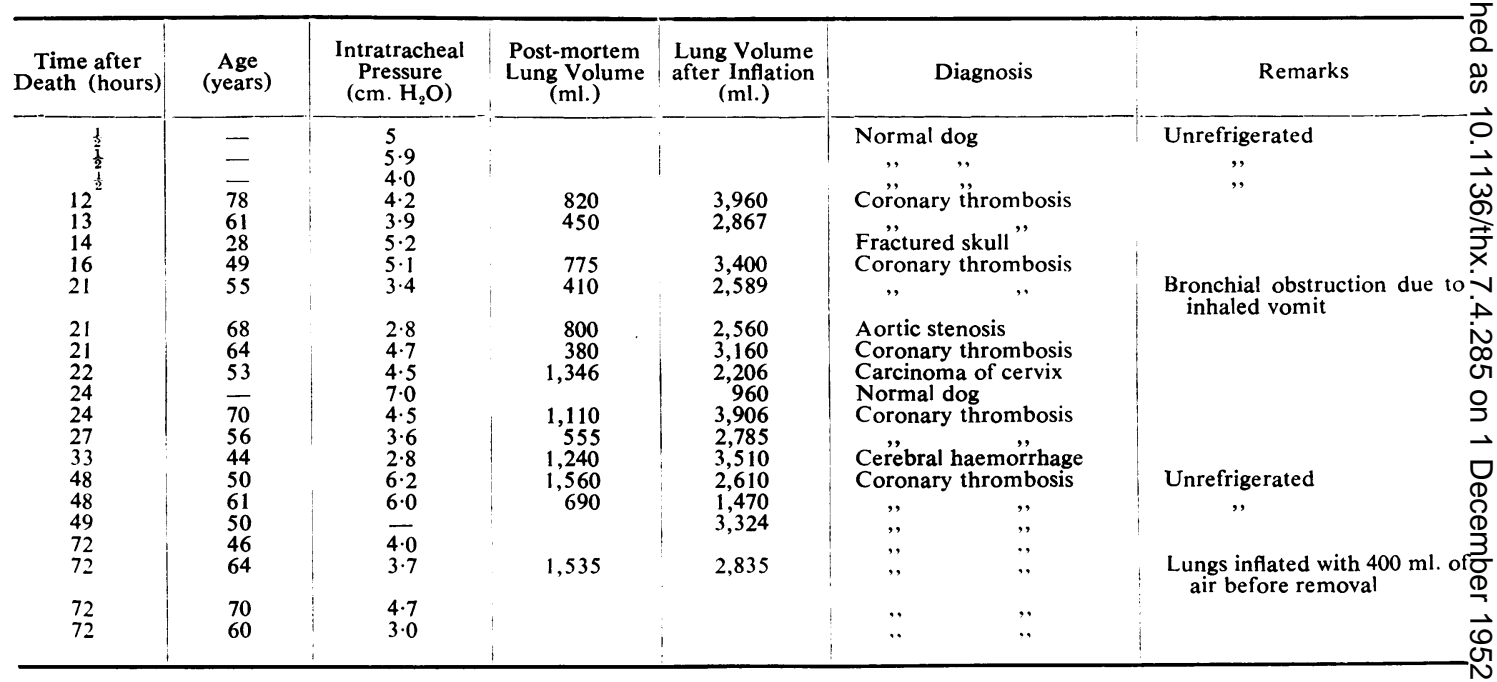

base line. After inflation $\mathrm{B}$ the pressure was increased to $-4.8 \mathrm{~cm}$. $\mathrm{H}_{2} \mathrm{O}$, but the volume level only returned to $850 \mathrm{ml}$. above the base line. After inflations $C$ and $D$ to -9.6 and $-12.0 \mathrm{~cm} . \mathrm{H}_{2} \mathrm{O}$ the lung volumes at a pressure of $-4.8 \mathrm{~cm} . \mathrm{H}_{2} \mathrm{O}$ were 1,020 and $1,800 \mathrm{ml}$. above the base line. In this experiment the lung volume at a pressure of $-4.8 \mathrm{~cm} . \mathrm{H}_{2} \mathrm{O}$ depended on the negative pressure to which the lungs had previously been subjected. Each time the pressure was reduced below its previous lowest level new alveoli opened and as a result the lung volume at a pressure of $-4.8 \mathrm{~cm} . \mathrm{H}_{2} \mathrm{O}$ became larger. When the plethysmograph was opened to the atmosphere ato the end of the experiment the lung volume returneds to its original level. From this tracing it can beo seen that the response of dead lungs to changes ino pressure in the plethysmograph clearly depends on $\mathbb{2}$ the previous history of inflation.

Another factor complicating the response of the lungs is the time taken to reach equilibrium following a change in pressure. In Fig. 3 two minutes were required before equilibrium was reached after inflation. Again in Fig. 4 one and? half minutes were required for equilibrium to bex reached at $\mathrm{D}$, and on opening the plethysmograph'

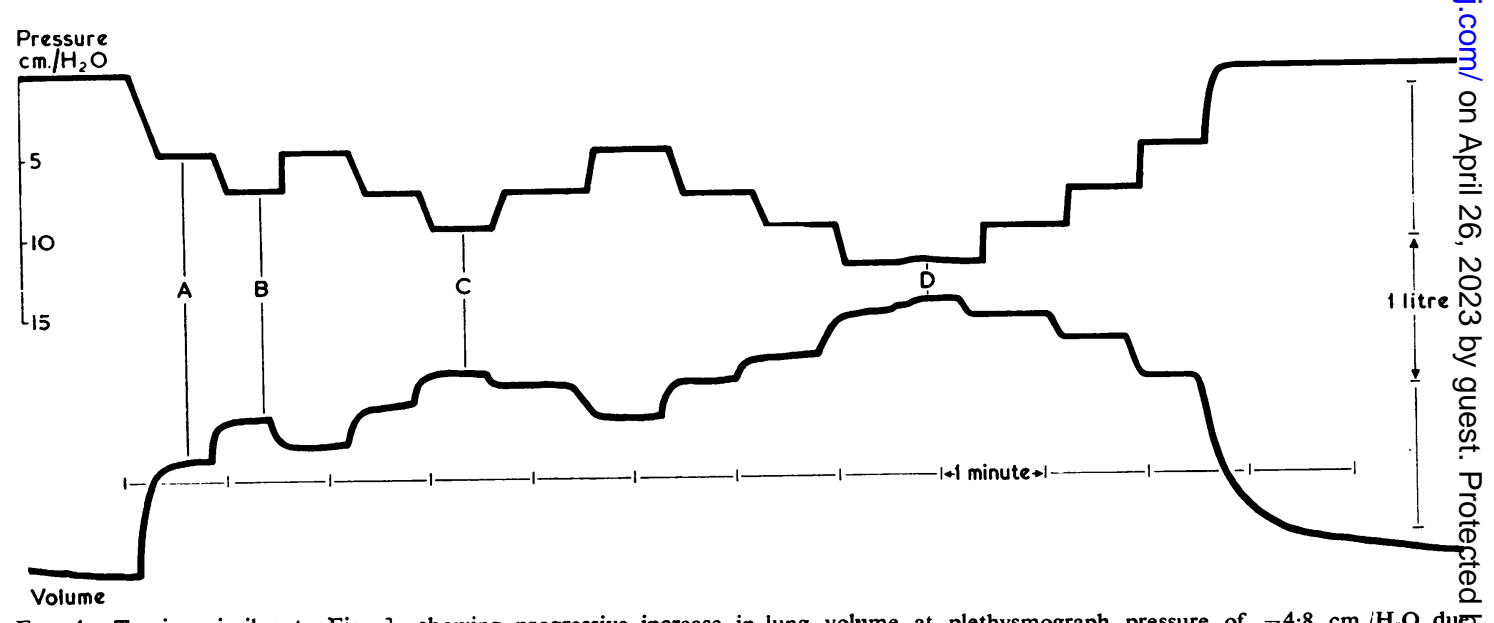

FIG. 4.-Tracing similar to Fig. 3, showing progressive increase in lung volume at plethysmograph pressure of $-4 \cdot 8 \mathrm{~cm} . / \mathrm{H}_{2} \mathrm{O}$, due to opening up of alveoli. After inflation $A$ to $-4 \cdot 8 \mathrm{~cm} . / \mathrm{H}_{2} \mathrm{O}$ lung volume is $770 \mathrm{ml}$. above base line; after inflation $\mathrm{B}$ to $-7 \cdot 1$ cm.
$850 \mathrm{ml}$. above base line; and after inflations $\mathrm{C}$ and $\mathrm{D}$ to $-9 \cdot 6$ and $-12 \cdot 0 \mathrm{~cm} . / \mathrm{H}_{2} \mathrm{O} 1,020 \mathrm{ml}$. and $1,800 \mathrm{ml}$. above the base line. 
Pressure

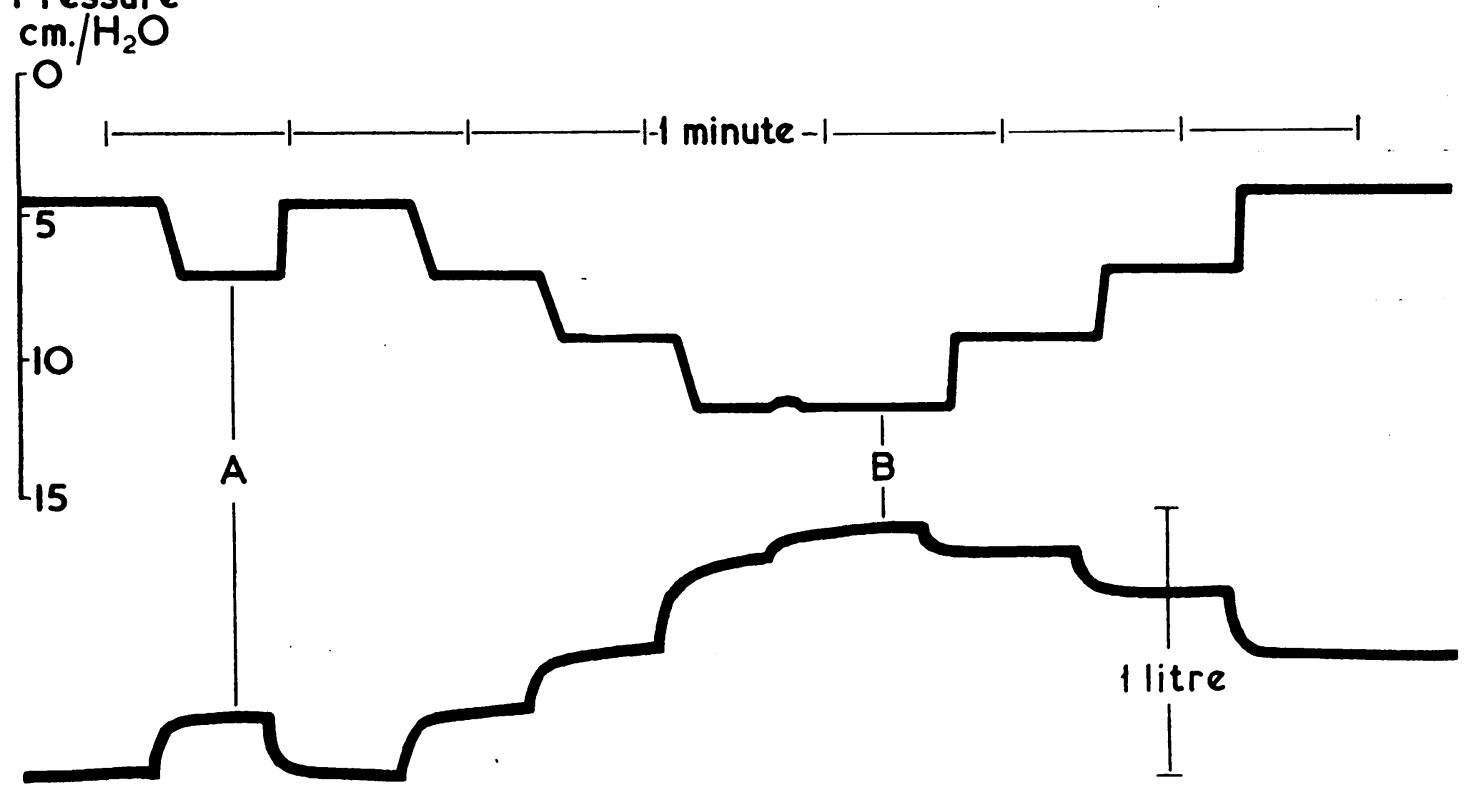

Volume

FIG. 5.-Tracing similar to Fig. 3, illustrating hysteresis after a large inflation. After smaller inflation A the lungs recoil completely. After the larger inflation B the lungs show hysteresis and fail to recoil completely.

to the atmosphere at the end of the experiment the lungs required time to reach equilibrium. The fact that time is required for equilibrium to be reached on inflation and recoil is evidence of the viscoelastic nature of the response of the lungs.

Variation in the number of alveoli open at different stages of inflation and the comparatively long time needed for equilibrium to be reached following a change of pressure were together responsible for the phenomenon of hysteresis, which was observed in all the lungs investigated. The term "hysteresis" has been used to describe the state of affairs in which the pressure-volume relationship on inflation differs from that on deflation. It is best illustrated by an example (Fig. 5). In the first inflation, $A$, there was no hysteresis, the volume at a given pressure level being the same before and after inflation. In the larger second inflation, $B$, there was hysteresis, for the volume at intermediate pressure steps during recoil was greater than at similar pressures during inflation. Hysteresis was observed in all inflations in which the pressure was reduced sufficiently to open up alveoli and was more marked when time was not allowed for equilibrium to be reached after inflation.

From the preceding description of the complex nature of the response of the lungs to inflation, it PRESSURE. cm. $/ \mathrm{H}_{2} \mathrm{O}$

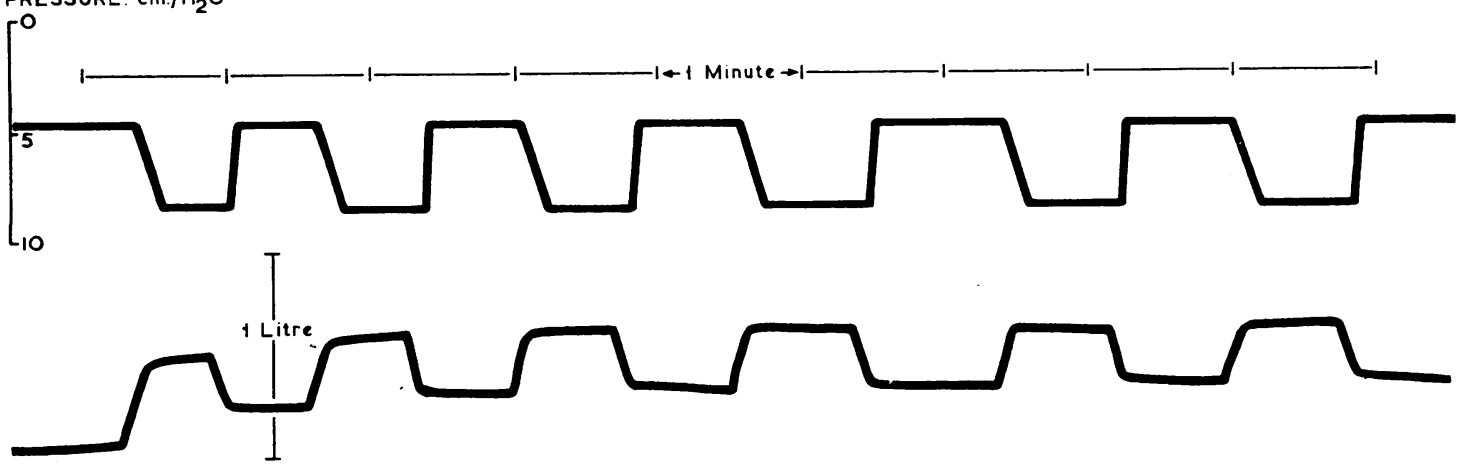

VOLUME

FIG. 6.-Tracing similar to Fig. 3, showing constant response to a constant pressure change repeated at intervals. 
TABLE IV

CHANGES IN DISTENSIBILITY* OF ANIMAL LUNGS AFTER DEATH

\begin{tabular}{|c|c|c|}
\hline Animal & Time after Death & Distensibility \\
\hline Dog & $\begin{array}{rc}30 & \text { minutes } \\
35 & \text {, } \\
3 & \text { hours } \\
7 & , \\
24 & , \\
30 & ,\end{array}$ & $\begin{array}{l}0.96 \\
1.37 \dagger \\
1.55 \\
2.0 \\
3.8 \\
4.8\end{array}$ \\
\hline Dog & $\begin{array}{rc}30 & \text { minutes } \\
40 & \text {, } \\
7 & \text { hours } \\
26 & ,,\end{array}$ & $\begin{array}{l}1.55 \\
1.8 \ddagger \\
2.0 \\
3.6\end{array}$ \\
\hline Rabbit & $\begin{array}{cc}10 & \text { minutes } \\
1 \frac{1}{2} & \text { hours } \\
3 & \text {, } \\
19 & \text { ", } \\
23 & \text {," }\end{array}$ & $\begin{array}{r}62 \\
58 \\
75 \\
100 \\
118\end{array}$ \\
\hline Rabbit & $\begin{array}{c}10 \text { minutes } \\
1 \frac{1}{2} \text { hours } \\
3 \\
8 \frac{1}{2} \quad, " \\
19 \quad,\end{array}$ & $\begin{array}{r}80 \\
88 \\
98 \\
100 \\
230\end{array}$ \\
\hline
\end{tabular}

* Distensibility is expressed as force in $\mathrm{cm} . / \mathrm{H}_{2} \mathrm{O}$ required to distend the lungs by $100 \mathrm{ml}$.

+ After opening plethysmograph to atmospheric pressure

¥ After increasing plethysmograph pressure to $-1 \mathrm{~cm} . / \mathrm{H}_{2} \mathrm{O}$.

is clear that distensibility varies with the lung volume and previous history of inflation in a complex and almost unpredictable manner. It was also found to vary with the passage of time after death. The results of experiments showing a progressive increase after death in the force required to inflate the lungs are given in Table IV.

The only predictable features which were demonstrated in these experiments concerned the elastic recoil of the lungs. The positive pressure generated in the trachea on opening the thorax was measured in 17 human lungs and varied from 2.8 to $6.2 \mathrm{~cm} . \mathrm{H}_{2} \mathrm{O}$ with a mean of $4.3 \mathrm{~cm}$. $\mathrm{H}_{2} \mathrm{O}$ (Table I). The time elapsing between death and necropsy had no effect on this measure of elastic recoil. It was also found that, if a small pressure change such as occurs in ordinary breathing during life was repeated, the volume change with each successive breath became constant (Fig. 6). This predictable behaviour is further described in the next paper.

\section{Discussion}

At least three factors are responsible for the failure of previous workers to obtain consistent results in studying the elastic properties of dead lungs. The first is failure to appreciate that considerable deflation of the lungs occurs in the first few hours after death. The second factor is failure to recognize that the lungs take a considerable time to reach a state of equilibrium following a change in pressure, and the third and perhaps most important factor is the difference between the behaviour of the lungs when suspended in the plethysmo graph and within the thorax. In the plethysmo음 graph deflation may be associated with collapse of certain alveoli, which are then held by surface tension so that considerable force is needed to operf them. In these circumstances the distensibility of the lungs depends largely on the proportion of alveoli which are patent, and this can neither bew predicted nor measured. The elastic recoil of the lungs will also be profoundly affected by this factor, for if collapsed alveoli are opened up on $N$ expansion the lungs will not recoil to their previous volume when the force is removed. It is clear thator in the conditions of these experiments, the behaviour of the lungs depends on the previous history of inflation or deflation.

The only circumstance in which a predictable response can be obtained is when exactly the same force is applied to the lungs on repeated occasion in a manner comparable to that which occurs in life. Under these circumstances a state of equilise brium is established in which the degree of inflat tion becomes constant. The significance of this constant response in analysing the elastic propertie of the lungs after death will be discussed in a late communication.

\section{SUMMARY}

The properties of normal human and anima $\vec{\Phi}$ lungs removed up to 72 hours after death have been investigated on inflation with negative pres sure in a plethysmograph. From measurements o? lung volume after death it is clear that a consider able volume of air is expelled from the lungs mainly in the first two hours after death.

The distensibility of the lungs after death varies in a complex and unpredictable manner, depending. on the number of alveoli open at any given time The response of the lungs to a change in pressure is visco-elastic, several minutes being required on occasions for equilibrium to be reached. A predict able response to inflation is only observed when $\bar{x}$. small pressure is applied to the lungs on repeatedy occasions. In these circumstances the volume off air entering the lungs with each inflation becomes constant.

The inability of previous workers to obtain con? sistent results in experiments with dead lungs probably due to their failure to recognize the changes in lung volume occurring after death, the visco-elastic nature of the response of the lungs and the possibility of infinite variation in the number of alveoli open after different degrees of inflation.

\section{REFERENCES}

Bates, D. V., and Christie, R. V. (1950). Clin. Sci., 9, 17. Carson, J. (1820). Philos. Trans., 110, 29. 